\title{
Neuroprotective Effects of Granulocyte Colony-Stimulating Factor on Ischemia-Reperfusion Injury of the Retina
}

\author{
Chieko Shima $^{a}$ Yasushi Adachi ${ }^{b, e}$ Keizo Minamino ${ }^{a}$ Mitsuhiko Okigaki $^{f}$ \\ Ming Shi $^{b}$ Yuichiro Imai ${ }^{c}$ Seiji Yanai ${ }^{d}$ Kanji Takahashi ${ }^{a}$ Susumu lkehara ${ }^{b}$ \\ Departments of a Ophthalmology, ${ }^{b}$ Stem Cell Disorders, ${ }^{c}$ Pediatrics, and d Surgery, Kansai Medical University, \\ Moriguchi City, ${ }^{e}$ Division of Clinical Pathology, Toyooka Hospital, Toyooka City, and ${ }^{\mathrm{f}}$ Department of Cardiovascular \\ Medicine, Kyoto Prefectural University School of Medicine, Kyoto, Japan
}

\section{Key Words}

Ischemia reperfusion $\cdot$ Granulocyte colony-stimulating factor - Neuroprotection - Phosphorylated AKT ·

Antiapoptosis $\cdot$ Inner retinal layer $\cdot$ TUNEL assay

\begin{abstract}
Purpose: It has been reported that granulocyte colony-stimulating factor (G-CSF) provides neuroprotection in models in which neuronal cell death is induced. This research was designed to investigate the effects of G-CSF on neurodegeneration of the inner retinal layer in a rat model of ischemic reperfusion (I/R) injury. Materials and Methods: Retinal ischemia was induced by increasing the intraocular pressure to $110 \mathrm{~mm} \mathrm{Hg}$ for $45 \mathrm{~min}$ in the left eyes of the rats. A sham operation was carried out on the right eyes. G-CSF (100 $\mu \mathrm{g} /$ $\mathrm{kg} /$ day in $0.3 \mathrm{ml}$ saline) or the same volume of saline was intraperitoneally injected just before the operation and continued for 4 consecutive days (a total of 5 consecutive days). Morphological examinations, including the terminal deoxynucleotidyl transferase dUTP nick end labeling (TUNEL) assay, were performed 7 days after I/R induction. The expression of phosphorylated AKT in the retina was examined by Western blot analysis and immunohistochemistry. Results: Cell loss in the ganglion cell layer was more significantly reduced in the I/R-induced eyes of the G-CSF-injected rats
\end{abstract}

than in the I/R-induced eyes of the saline-injected rats (20.3 vs. $6.6 \%)$. The inner retinal thickness ratios, such as the inner plexiform layer to the inner limiting membrane/outer nuclear layer and the inner nuclear layer/outer nuclear layer, were significantly better preserved in the I/R-induced eyes of the G-CSF-injected rats than in the I/R-induced eyes of the saline-injected rats. TUNEL assays showed fewer apoptotic cells in the retinal sections of the I/R-induced eyes of the GCSF-injected rats. The phosphorylation of AKT ( $p$-AKT/AKT) was upregulated in the retinas of the I/R-induced eyes of the G-CSF-injected rats. Conclusion: Our results demonstrated that systemic injection of G-CSF can protect retinal ganglion cells and inner retinal layers from I/R injury. The effects could be associated with the activation of AKT.

Copyright $\odot 2012$ S. Karger AG, Basel

\section{Introduction}

Granulocyte colony-stimulating factor (G-CSF) has previously been used extensively for treating chemotherapy-induced neutropenia, as well as for reconstituting bone marrow and mobilizing stem cells, and has a favorable safety profile [1]. G-CSF promotes the differentiation, proliferation and survival of neutrophilic lineage cells [2] and mobilizes hemopoietic stem cells to move

\section{KARGER}

Fax +41613061234

E-Mail karger@karger.ch

www.karger.com
(C) 2012 S. Karger AG, Basel

0030-3747/12/0484-0199\$38.00/0

Accessible online at:

www.karger.com/ore
Prof. Susumu Ikehara

Department of Stem Cell Disorders, Kansai Medical University

10-15 Fumizono-Cho, Moriguchi City, Osaka (Japan) 570-8506

Tel. +81 66993 9625, E-Mail ikehara@ takii.kmu.ac.jp 
from bone marrow into peripheral blood [3]. Moreover, it has been shown that G-CSF has antiapoptotic effects [4]. It has also been reported that the G-CSF receptor is widely expressed in the central nervous system and the retina [5-7], and that G-CSF is able to cross the blood-brain barrier [5]. Recently, antiapoptotic and neuroprotective effects of G-CSF in the central nervous system were identified using models for cerebral ischemia $[8,9]$, Parkinson's disease [10], Alzheimer's disease [11], spinal cord injury [12], and amyotrophic lateral sclerosis [13]. G-CSF is currently in phase I/II trials for ischemic stroke in humans [14]. In addition, the neuroprotective effects of G-CSF for retinal diseases have been reported using models for light-induced damage [6], optic nerve crush $[15,16]$ and oxygen-induced retinopathy [17]. Moreover, there have been reports of the functional neuroprotective effects of the retinal ischemia reperfusion (I/R) model by G-CSF [18]. However, the mechanisms by which G-CSF prevents retinal damage have remained unclear.

Pressure-induced I/R injury has been reported to be a model of central retinal artery occlusion and acute angle closure glaucoma because of similarities in the pathological changes that take place in those diseases, such as cell death of the ganglion cells and amacrine cells [19, 20]. In this model, cell death is induced by elevated intraocular pressure (IOP) [21] through both apoptosis and necrosis [22]. The peak cell death is 7 days after the injury, and no cell death is induced thereafter [23]. Of the endogenous components, glutamate, oxygen-free radicals, nitric oxide and calcium could be related to cell death in ischemic injury $[19,20]$.

In this study, we investigated whether G-CSF has a neuroprotective effect on pressure-induced I/R injury histologically, and the mechanisms by which G-CSF prevents retinal damage.

\section{Materials and Methods}

Animals

Adult male Sprague-Dawley rats (7-8 weeks old), weighing 210-290 g, were purchased from SLC (Shizuoka, Japan) for this experiment. The animals were treated according to the regulations in the ARVO Statement for the Use of Animals in Ophthalmic and Vision Research. The rats had free access to food and water and were maintained in cages in an environmentally controlled room with a temperature of $22 \pm 2{ }^{\circ} \mathrm{C}$, and a 12-hour lightdark cycle (light period: 8.00 to 20.00).

\section{Induction of Retinal $I / R$}

Retinal I/R was induced as previously described [24], but with slight modifications. Briefly, the rats were anesthetized by isoflu- rane inhalation using a gas anesthetizing system (MRTechnology, Inc., Ibaragi, Japan). Subsequently, $0.4 \%$ oxybuprocaine chlorhydrate anesthetic was applied topically to the eye. The pupils were dilated with an eye drop of $2.5 \%$ phenylephrine chlorhydrate and $0.5 \%$ tropicamide. The anterior chamber of the animal was cannulated with a 30 -gauge needle (Nipro Corporation, Nagano, Japan) connected to a reservoir containing saline solution $(0.9 \%$ sodium chloride; Otsuka Pharmaceutical, Tokyo, Japan). Retinal ischemia was induced by raising the reservoir, thereby increasing the IOP to $110 \mathrm{~mm} \mathrm{Hg}\left(150 \mathrm{~cm} \mathrm{H}_{2} \mathrm{O}\right)$ for $45 \mathrm{~min}$. Retinal ischemia was confirmed by the whitening of the anterior segment of the eye and the loss of the red reflex of the fundus. After $45 \mathrm{~min}$, the needle was removed, and reperfusion was confirmed by the reappearance of the red reflex. $0.3 \%$ ofloxacin ointment was applied in the conjunctival sac at the end of the experiment.

\section{G-CSF Injection and Peripheral White Blood Cell Count}

Human recombinant G-CSF (100 $\mu \mathrm{g} / \mathrm{kg})$, which was kindly donated by Chugai Pharmaceutical Co., Ltd. (Tokyo, Japan), was intraperitoneally injected into the rats for 5 consecutive days. As a control, the same volume of saline was intraperitoneally injected into the rats for 5 consecutive days.

To confirm the effect of G-CSF, $2 \mathrm{ml}$ of peripheral blood was obtained from the rat hearts 7 days after the start of G-CSF or saline injection, and the white blood cell (WBC) counts were then analyzed by SF-3000 auto-analyzer for the peripheral blood (Sysmex, Kobe, Japan).

\section{Experimental Groups and Treatment Schedules}

The right eyes of the rats received sham operation, which was carried out by inserting a needle into the anterior chamber without elevation of the IOP. Meanwhile, I/R was induced in the left eyes.

G-CSF, or the same volume of saline as G-CSF, was injected into the rats just before I/R induction, and G-CSF or saline was injected into the rats for 5 consecutive days.

The rats were euthanized 7 days or 1 day after I/R induction by isofluran and intraperitoneal administration of an overdose of $150 \mathrm{mg} / \mathrm{kg}$ body weight sodium pentobarbital (Escarnakon; Streuli Pharma SA, Uznach, Switzerland). Both eyes were enucleated for histological examination, immunostaining and Western blot analyses.

In the histological examination, there were no significant differences in the retina between eyes of non-treated rats, the right eyes (sham-operated eyes) of saline-injected rats and the right eyes (sham-operated eyes) of G-CSF-injected rats. Therefore, we show the data for the right eyes in the saline-injected rats as a representative of those eyes.

\section{Histological Examination}

After corneal incision, the eyes were fixed in a metacarn solution (methanol:chloroform:acetic acid $=1: 3: 1$ ) overnight for the staining of hematoxylin (Hematoxylin; Merck, Darmstadt, Germany) and eosin (Eosin Y; Wako Pure Chemical industries, Ltd., Osaka, Japan), or the eyes were fixed in super fix (Kurabo industries Ltd., Osaka, Japan) overnight for terminal deoxynucleotidyl transferase dUTP nick end labeling (TUNEL) staining and immunohistochemistry. The eyes were then processed for routine paraffin-embedded sections on an automatic tissue processor (Sakura Finetek Japan Co., Ltd., Tokyo, Japan). The eyes were em- 
bedded sagitally, and 5- $\mu \mathrm{m}$-thick serial sections including the optic nerve were prepared using a rotary microtome (Leica Microsystem, Wetzlar, Germany). To compare groups, we used the methods described by Zhu et al. [25], but with slight modifications, such as using image analysis software (DP2-BSW; Olympus Corporation, Tokyo, Japan) and measuring the thickness of the different retinal layers in triplicate in both the superior and inferior retina at a fixed distance $(750-1,000 \mu \mathrm{m})$ from the edge of the optic disc. A minimum of three sections were prepared for each eye. In the morphometric analyses, we measured the distance from the inner plexiform layer to the inner limiting membrane (IPL-ILM) and the thickness of the inner nuclear layer (INL) and the outer nuclear layer (ONL). We calculated the averages of IPLILM/ONL and INL/ONL ratios in each eye, and also counted the number of morphologically identified viable cells (half these would be ectopic amacrine cells) in the ganglion cell layer (GCL) in the same topographic region. This manual cell count in the GCL was performed over a length of $250 \mu \mathrm{m}$. Means of more than 6 measurements per eye were calculated. All morphometric measurements were performed in a masked fashion.

TUNEL assay (In Situ Cell Death Detection Kit, Takara Bio Inc., Shiga, Japan) was performed to detect retinal cell death, according to the manufacturer's protocol. The number of TUNELpositive cells in ONL and INL-GCL were counted in each $200-\mu \mathrm{m}$ wide section at a distance of $1 \mathrm{~mm}$ from the edge of the optic nerve. The average was calculated from 12 measurements of six sections per eye.

Western Blot Analysis of Phosphorylated AKT

Seven days after I/R induction, Western blot analysis of phosphorylated AKT (p-AKT) was performed by standard protocols [26] with slight modifications. Rat retinas were isolated and sonicated in Laemmli sample buffer (Bio-Rad Laboratories, Calif., USA) and protease inhibitor cocktail (Bio-Rad Laboratories). The lysate was centrifuged at $14,000 \mathrm{rpm}$ for $30 \mathrm{~min}$ and the supernatant was prepared. The same amount of samples was prepared using a standard concentration of bovine serum albumin. Protein samples containing $10 \mu \mathrm{g}$ of protein were separated on $10 \%$ sodium dodecyl sulfate-polyacrylamide gels (Oriental Instruments Ltd., Tokyo, Japan) with a size marker (Amersham, UK) and transferred to polyvinylidene difluoride membranes (Bio-Rad Laboratories). The membranes were incubated in blocking buffer (Roche Diagnostics GmbH, Mannheim, Germany) for 60 min to block nonspecific binding. Primary antibodies were added and the preparations were incubated overnight at $4^{\circ} \mathrm{C}$. The primary antibodies included anti-rabbit p-AKT (Ser473, rabbit IgG 1:2,000; Cell Signaling Inc., Danvers, Mass., USA), AKT (pan, C67E7, rabbit IgG 1:1,000; Cell Signaling) and $\beta$-actin (1:5,000; Abcam, Cambridge, Mass., USA) antibodies. The membranes were washed with washing buffer (Roche Diagnostics) followed by incubation with horseradish peroxidase-conjugated secondary antibody (1:5,000; Santa Cruz Biotechnology, Inc., Santa Cruz, Calif., USA) for $1 \mathrm{~h}$ at room temperature. The blot was then washed with washing buffer. Protein bands detected by the antibodies were visualized by ECL plus reagent (GE Healthcare, Chalfont St. Giles, UK) on a luminescent image analyzer (RAS 4000mini; Bucher Biotech, Basel, Switzerland). Quantification was performed on a computer using Image J software (National Institutes of Health, Bethesda, Md., USA). To determine the activated AKT, the percentage of activated AKT was defined as p-

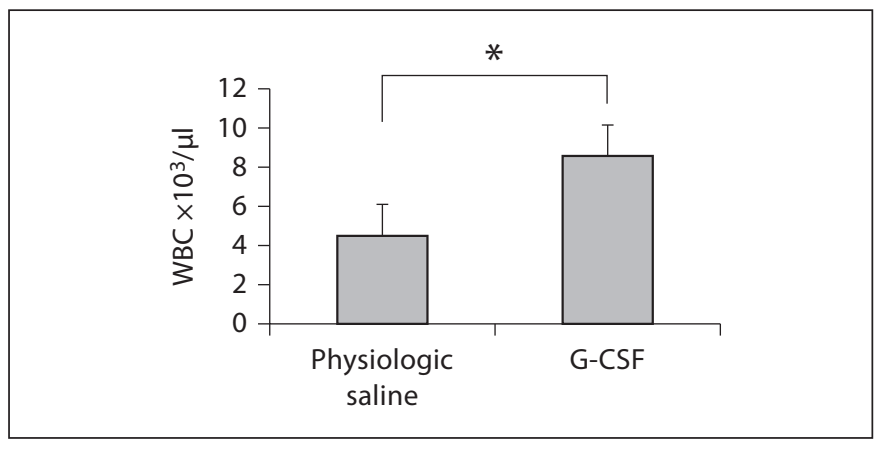

Fig. 1. G-CSF can augment WBC counts in peripheral blood in rats. G-CSF or saline was injected into the rats for 5 consecutive days. Seven days after the start of G-CSF or saline injection, peripheral blood was obtained from the rats and $\mathrm{WBC}$ counts were analyzed ( $n=6$ in each group). ${ }^{*} p<0.05$.

AKT/total AKT. To confirm equal protein loading, the expression of $\beta$-actin was examined in each Western blot.

\section{Immunohistochemistry of $p-A K T$ in the Retina}

To detect $\mathrm{p}$-AKT protein expression in the retina, $\mathrm{p}$-AKT immunostaining was performed according to the manufacturer's protocol 7 days after I/R induction. Paraffin-embedded sections as described in Histological Examination were deparaffinized with xylene and dehydrated through a graded ethanol series. They were then boiled for $20 \mathrm{~min}$ in citrate buffer ( $\mathrm{pH}$ 6.0) for antigen retrieval and incubated with $3 \%$ hydrogen peroxide solution for $10 \mathrm{~min}$ at room temperature to inhibit endogenous peroxidase activity. Primary antibody of p-AKT (1:25; Cell Signaling) was added and incubated at $4^{\circ} \mathrm{C}$ overnight. The samples were then washed and exposed to Histofine Simple Stain MAX PO (MULTI; Nichirei Bioscience, Tokyo, Japan) secondary antibody for $1 \mathrm{~h}$ at room temperature. Finally, they were visualized by the use of DAB. Hematoxylin was used for counterstaining. Positive control sections (Cell Signaling) were stained to confirm the applicability of this system, while the solution for dilution (Cell Signaling) was used as negative control.

\section{Statistical Analysis}

All measurements in this study were performed in a masked fashion. Mean values with standard deviations (SDs) were obtained and are presented here. Significant differences among the groups were examined using Student's t test. Statistical significance was declared if the $\mathrm{p}$ value was $<0.05$.

\section{Results}

\section{Administration of G-CSF and Peripheral WBC Counts}

First, we examined whether intraperitoneal administration of G-CSF could augment the number of WBCs in the peripheral blood 7 days after I/R induction. When G- 
Fig. 2. Histological examination of $I / R$ injury and inhibitory effect of G-CSF on retinal damage. a G-CSF, or the same volume of saline, was injected into the rats just before I/R induction, and G-CSF or saline was injected into the rats for 5 consecutive days. Seven days after I/R injury, the rats were sacrificed and the eyes were examined. Specimens of the sham-operated eyes of saline-injected rats (sham + saline), the I/R-induced eyes of the saline-injected rats (I/R + saline) and the I/R-injected eyes of the G-CSF-injected rats (I/R + G-CSF) were prepared, and RGC cell numbers, IPL-ILM/ONL and INL/ONL ratios were calculated, as described in Materials and Methods. Representative data are shown. $\times 400$. b The number of morphologically identified viable cells in the GCL was counted in triplicate in both the superior and inferior retina at a fixed distance (750-1,000 $\mu \mathrm{m})$ from the edge of the optic disc. Means \pm SDs of the data are shown ( $\mathrm{n}=7$ in each group). ${ }^{*} \mathrm{p}<0.05$. c The thickness of the different retinal layers was measured in both the superior and inferior retina at a fixed distance $(750-1,000 \mu \mathrm{m})$ from the edge of the optic disc. Means \pm SDs of the data are shown ( $n=7$ in each group). ${ }^{*} \mathrm{p}<0.05$.

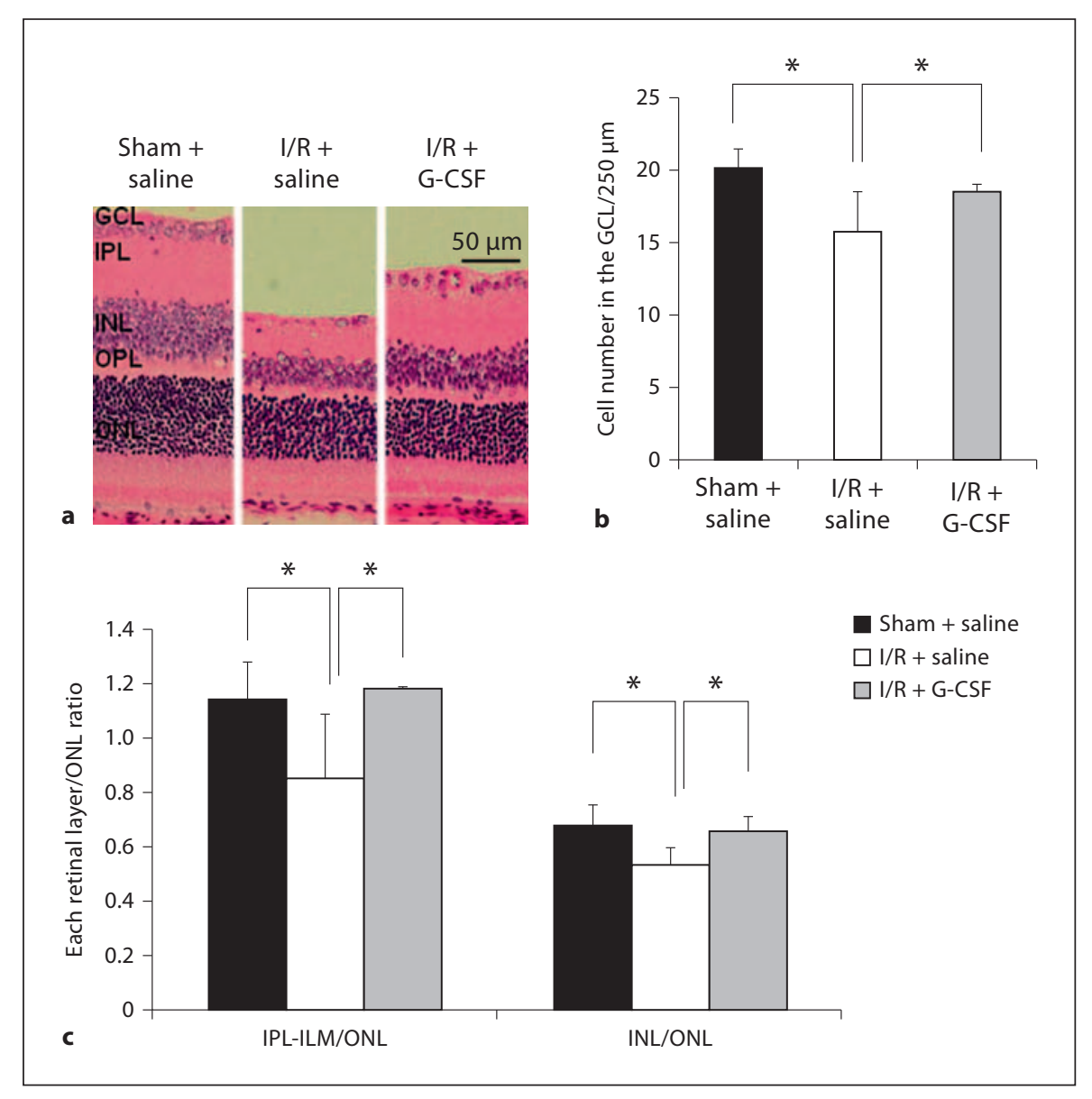

CSF $(100 \mu \mathrm{g} / \mathrm{kg})$ was intraperitoneally injected into Sprague-Dawley rats for 5 consecutive days, the number of WBCs in the peripheral blood of the rats reached 8.58 $\pm 1.63 \times 10^{3} / \mu \mathrm{l}$. On the other hand, when saline was injected instead of G-CSF, the number of WBCs was 4.46 $\pm 1.59 \times 10^{3} / \mu \mathrm{l}$ (fig. 1). The numbers of erythrocytes and platelets did not change significantly (data not shown). These results suggest that G-CSF can specifically augment the number of WBCs in the peripheral blood.

\section{Histopathological Examination}

Figure 2 shows the changes in cell numbers in the GCL and the IPL-ILM/ONL and INL/ONL ratios after I/R induction. We histologically evaluated neural cell damage using these cell numbers and ratios. Cell loss in the GCL in the I/R-induced eyes of the saline-injected rats and the I/R-induced eyes of the G-CSF-injected rats was $20.3 \%$ $(19.74 \pm 1.74$ to $15.74 \pm 2.68)$ and $6.6 \%(19.74 \pm 1.74$ to $18.43 \pm 0.63$ ), respectively (fig. 2b). Therefore, cell loss was significantly suppressed $(\mathrm{p}=0.0336)$ in the I/R-induced eyes of the G-CSF-injected rats in comparison with the I/R-induced eyes of the saline-injected rats. In the shamoperated eyes of saline-injected rats, the IPL-ILM/ONL and INL/ONL ratios were $1.14 \pm 0.14$ and $0.67 \pm 0.08$, respectively. The IPL-ILM/ONL ratio in the I/R-induced eyes of the saline-injected rats was $0.85 \pm 0.24$, while the IPL-ILM/ONL ratio in the I/R-induced eyes of the G-CSFinjected rats was $1.18 \pm 0.15$ (fig. 2 c). There was a significant difference between these groups $(\mathrm{p}=0.0151)$. The INL/ONL ratios in the I/R-induced eyes of the saline-injected rats and the I/R-induced eyes of the G-CSF-injected rats were $0.53 \pm 0.07$ and $0.65 \pm 0.09$, respectively (fig. $2 c$ ). There was a significant difference between these groups $(p=0.0173)$. There were no significant differences between the sham-operated eyes of the saline-injected rats and the I/R-induced eyes of the G-CSF-injected rats.

Therefore, G-CSF treatment reduced the ganglion cell loss and preserved the IPL-ILM/ONL and INL/ONL ratio. These results indicate that G-CSF protected the ganglion cell inner retinal layer. 


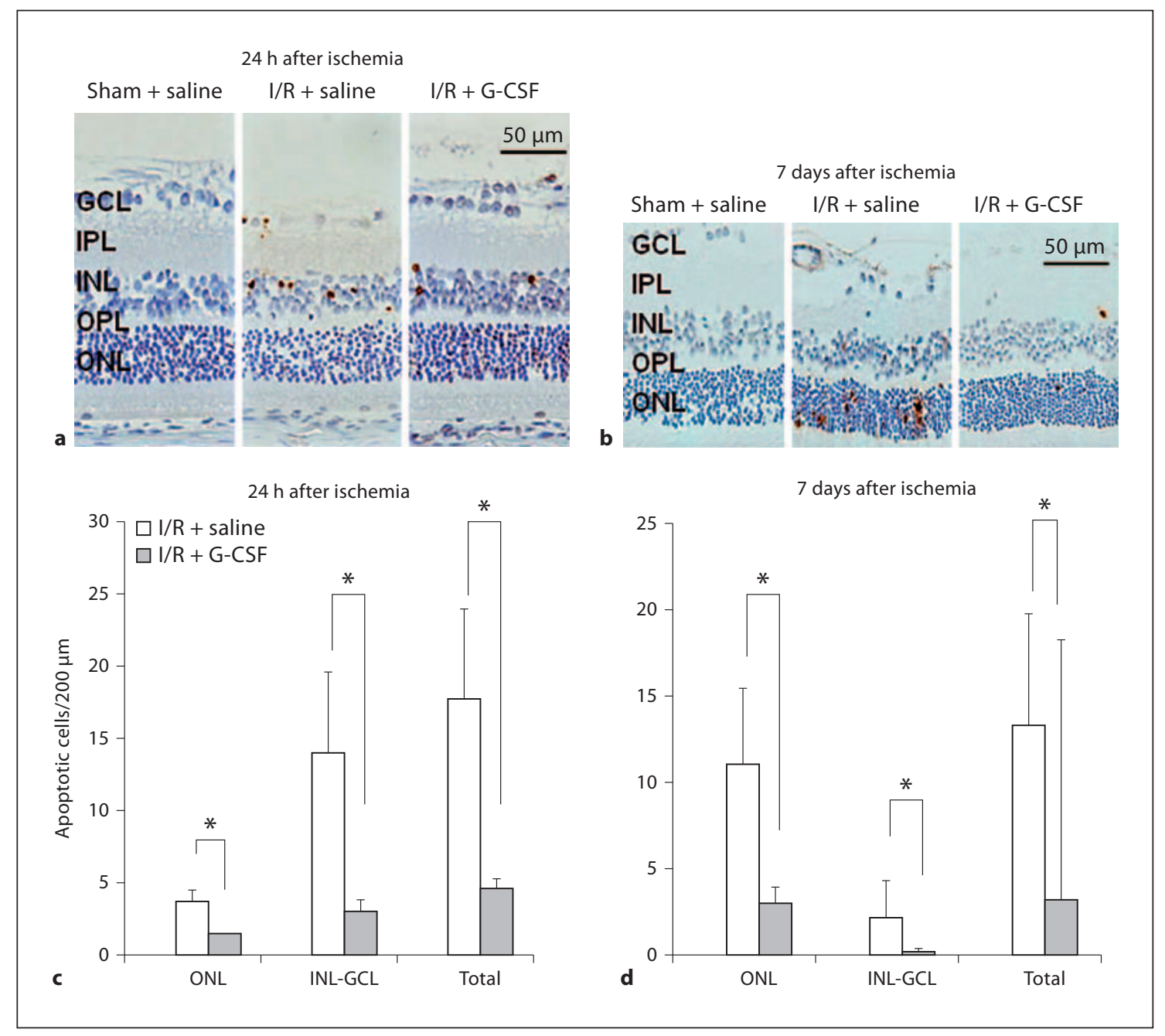

Fig. 3. G-CSF can reduce the apoptosis of RGC after I/R injury. TUNEL staining of retinal sections at $24 \mathrm{~h}$ and 7 days after I/R injury. a In the sham-operated eyes of the saline-injected rats (sham + saline), there were no TUNEL-positive cells. In the I/Rinduced eyes of the saline-injected rats (I/R + saline), small numbers of TUNEL-positive cells were detected in the GCL and INL at $24 \mathrm{~h}$ after I/R induction. Representative data are shown. b In

\section{Examination of Apoptotic Cells by TUNEL Assay}

It has been reported that the time course of cell death is different in the various retinal layers. For example, cell death occurs first in the GCL and last in the ONL. In the inner retinal layers, the number of TUNEL-positive cells reached a peak at $24 \mathrm{~h}$ after I/R induction, followed by cell loss at day 7. In the ONL, TUNEL-positive cells reached a peak at $48 \mathrm{~h}[27,28]$. Therefore, we carried out the TUNEL assay 1 day and 7 days after I/R induction. DNA fragmentation was detected using the TUNEL technique in each layer. No TUNEL-positive cells were detected in the eyes, TUNEL-positive cells were detected mainly in the ONL at 7 days after I/R induction. Representative data are shown. c, d Number of TUNEL-positive cells in each retinal layer. TUNEL-positive cells per $200 \mu \mathrm{m}$ of each retinal layer were counted, as described in Materials and Methods. At least 24 images from 4 eyes were prepared per group. Means \pm SDs of the data are shown ( $n=4$ in each group). ${ }^{*} \mathrm{p}<0.05$.

retinal tissue sections obtained from the sham-operated eyes of the saline-injected rats. TUNEL-positive cells were detected mainly in the INL at $24 \mathrm{~h}$ after reperfusion (fig. 3a). Seven days after I/R induction, TUNEL-positive cells were detected mainly in the ONL (fig. 3b). The mean number of TUNEL-positive cells in the INL-GCL at $24 \mathrm{~h}$ after I/R induction was 14 cells/200 $\mu \mathrm{m}$ in the I/R-induced eyes of the saline-injected rats and 3.1 cells $/ 200 \mu \mathrm{m}$ in the I/R-induced eyes of the G-CSF-injected rats, respectively $(\mathrm{p}=0.008)$. In the ONL, the number of TUNEL-positive cells at $24 \mathrm{~h}$ was 3.58 cells $/ 200 \mu \mathrm{m}$ in the 
Fig. 4. Analysis of p-AKT expression in the rat retina at 7 days after $\mathrm{I} / \mathrm{R}$ induction. a, b Quantitative data of AKT phosphorylation by Western blot analysis. At 7 days after I/R induction, $10 \mu \mathrm{g}$ of retinal protein was examined by Western blot analysis, as described in Materials and Methods. Means \pm SDs of the data are shown $(n=4$ in each group). ${ }^{*} \mathrm{p}<0.05$. c Immunostaining of paraffin sections of the retina for $\mathrm{p}$ $\mathrm{AKT}$ at 7 days after I/R induction. Immunostaining of the eyes at 7 days after $\mathrm{I} / \mathrm{R}$ induction was carried out as described in Materials and Methods. Representative data are shown from 4 independent experiments. $\times 400$.

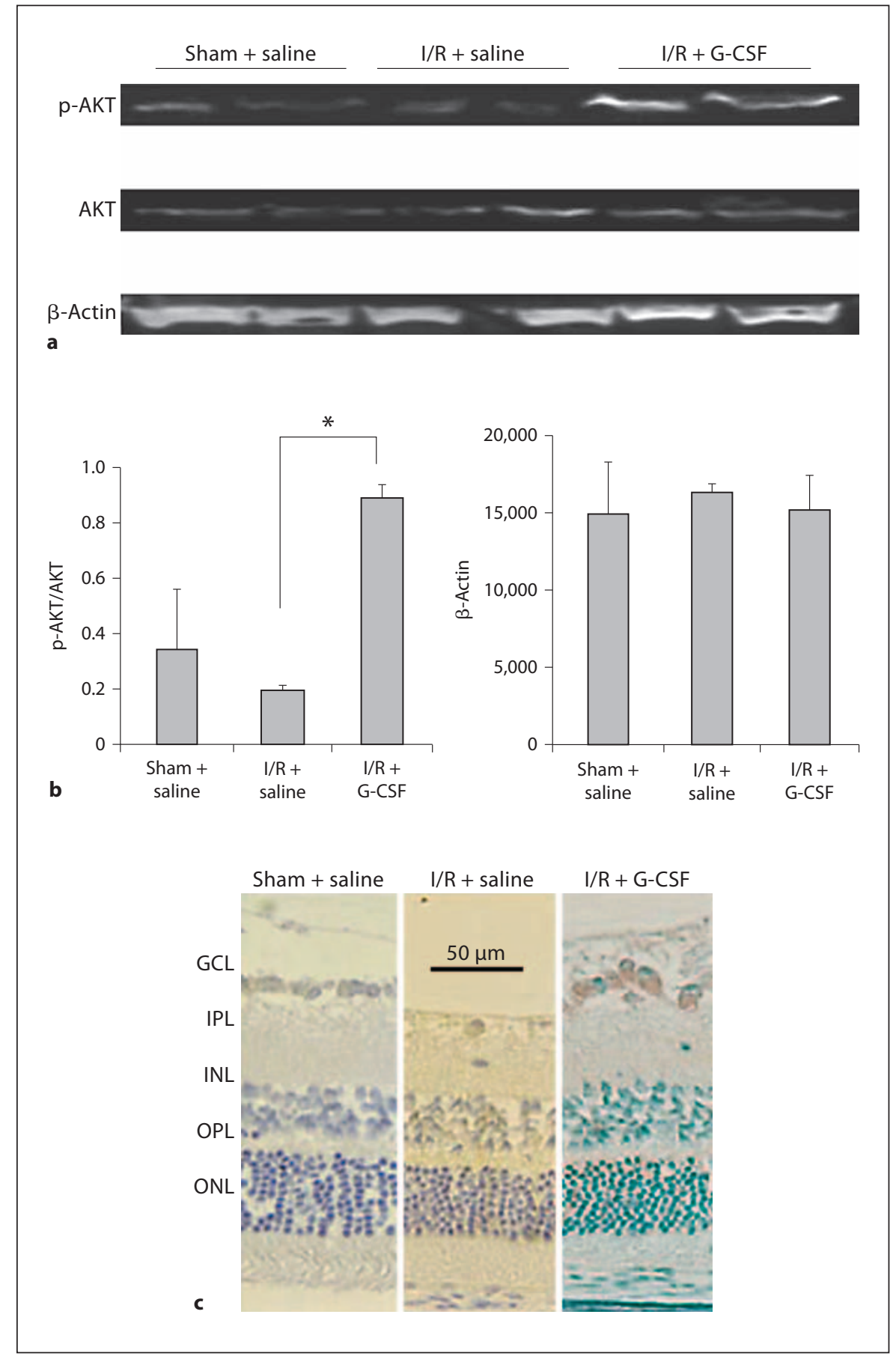

I/R-induced eyes of the saline-injected rats and 1.5 cells/200 $\mu \mathrm{m}$ in the I/R-induced eyes of the G-CSF-injected rats, respectively $(\mathrm{p}=0.005$; fig. $3 \mathrm{c})$. On the other hand, 7 days after I/R induction, the mean number of TUNEL-positive cells in the INL-GCL was 2.17 in the I/R-induced eyes of the saline-injected rats, and 0.17 in the I/R-induced eyes of the G-CSF-injected rats, respectively $(\mathrm{p}=0.043)$. The number of TUNEL-positive cells in the ONL was 11.1 cells $/ 200 \mu \mathrm{m}$ in the I/R-induced eyes of the saline-injected rats and 3.00 cells $/ 200 \mu \mathrm{m}$ in the I/R-induced eyes of the G-CSF-injected rats, respectively $(\mathrm{p}=0.005$; fig. $3 \mathrm{~d})$. 
These results demonstrated that administration of GCSF had a significant anti-apoptotic effect on I/R injury.

Western Blot Analysis of p-AKT

To examine the effect of retinal I/R induction and the injection of G-CSF on AKT activity, we carried out Western blot analysis of the p-AKT.

Seven days after I/R induction, phosphorylation of AKT increased in the I/R-induced eyes of the G-CSF-injected rats in comparison with the other groups, whereas AKT expression remained unchanged as compared with the other groups (fig. 4a). The p-AKT/AKT ratio was 0.26 in the sham-operated eyes of the saline-injected rats, 0.27 in the I/R-induced eyes of the saline-injected rats, and 0.81 in the I/R-induced eyes of the G-CSF-injected rats (fig. 4b). The expression of p-AKT in the I/R-induced eyes of the G-CSF-injected rats was about 3-fold higher than in the other groups $(\mathrm{p}=0.0154)$.

\section{Immunohistochemistry of $p-A K T$ in the Retina}

No positive cells in immunostaining for $\mathrm{p}$-AKT were found in any sections without primary antibody. There were few p-AKT-positive cells in the sham-operated eyes of the saline-injected rats. On the other hand, there were some positive cells for p-AKT in the I/R-induced eyes of the saline-injected rats, and the positive cells significantly increased in the I/R-induced eyes of the G-CSF-injected rats (fig. 4c). Most of the p-AKT-positive cells in the I/Rinduced eyes of the G-CSF-injected rats existed in the inner part of the retina and, particularly, in the GCL as compared with the I/R-induced eyes of saline-injected rats.

\section{Discussion}

In this study, we show that retinal ganglion cell (RGC) death caused by high IOP-induced transient ischemia was suppressed by G-CSF administration histologically. Moreover, we found that one of the mechanisms could be the antiapoptosis effect via the activation of AKT. Our results showed that the cell numbers in the GCL and ILM-IPL/ONL and INL/ONL ratios of the I/R-induced eyes of the G-CSF-treated rats were greater than those of the I/R-induced eyes of saline-injected rats 7 days after the I/R injury. In the TUNEL assay, the G-CSF injection reduced the number of apoptotic cells. We found that GCSF significantly augmented the expression of p-AKT in Western blot analysis.

The mechanisms underlying the neuroprotective effects of G-CSF are unclear. However, there are several hy-

Effects of G-CSF on Ischemia-Induced Retina potheses: the first is that there are direct effects, including anti-apoptotic and anti-inflammatory processes, at the site of injury [15]. Anti-inflammatory effects occur via the inhibition of the inducible nitric oxide synthase, the suppression of tumor necrosis factor- $\alpha$ and the reduction in interleukin- $1 \beta$ expression $[9,29]$. The second hypothesis is that there are indirect effects, including the stimulation of neurogenesis, recruitment of bone marrow stromal cells $[5,30]$, and the promotion of angiogenesis [31]. All these might act in synergy to induce the neuroprotective response observed in a variety of different retinal injury models when G-CSF has been administered.

However, it is likely that the neuroprotective effects afforded by G-CSF administration are induced through $\mathrm{G}$-CSF receptors in the direct effects, since previous studies have shown that G-CSF reduced the migration of bone marrow-derived monocytes/macrophages and augmented the intrinsic microglia/macrophages at the ischemic site by using bone marrow chimera mice expressing enhanced green fluorescent protein [9]. Optic nerve crush studies have shown that G-CSF has potent neuroprotective effects for preventing RGC death induced by optic nerve crush when G-CSF was administered systemically or topically. The antiapoptotic effect could be directly mediated via the G-CSF receptor expressed on neural cells $[5,16]$. It has also been reported that G-CSF receptor expression is induced upon cerebral ischemia, suggesting that an autocrine protective signaling mechanism is at work in ischemia $[5,32,33]$. Thus, we hypothesized that the direct effect, especially the antiapoptotic effect from G-CSF administration, may be involved in I/R injury. In this study, we have observed that the administration of G-CSF had a significant antiapoptotic effect in I/R injury.

G-CSF combines with the G-CSF receptor and activates signal pathways such as Jak/Stat, PI3K/AKT and MAPK/Akt $[5,6,8,9]$. Among these pathways, activation of PI3K/AKT is believed to have the most powerful antiapoptotic effects upon administration of G-CSF [5]. AKT is one of the components of the PI3K pathway. It has been reported that the AKT pathway is activated after optic nerve clamping [34], intravitreal injection of N-methyl$D$-aspartate [35, 36], episcleral vein cauterization $[37,38]$ and translimbal photocoagulation [39], suggesting that it is a common response of the retina to detrimental stimuli. Thus, we examined the activated AKT to investigate the mechanisms of the antiapoptotic effects by G-CSF administration.

In this study, we have observed that PI3K/AKT was activated not only just after I/R induction but also 7 days 
after I/R induction. These results suggest that the status of AKT activation induced by I/R injury continues longterm and works for neuroprotection. Moreover, we have observed that the activated p-AKT is found mainly in the GCL. These observations suggest that activation of AKT may prevent apoptotic death after I/R injury and, also, that it may explain the selective protection of the inner retina as well. However, it is still unclear how G-CSF affects retinal AKT 3 days after its injection, and whether other mechanisms, including other signal pathways, mediate these effects. These questions need to be addressed in future studies.

Only a few side effects of G-CSF have been reported. Moreover, it has been reported that leukocytosis by GCSF was restricted to the vessel compartment and that it had no deleterious effects on lesion function and recovery [40]. Therefore, we believe that G-CSF could be used safely for neuroprotection even in human beings. G-CSF is used clinically and has a good safety profile, suggesting that it could rescue RGC from death in ophthalmic disorders such as glaucoma, optic neuropathies and various retinovascular diseases. Therefore, systemic G-CSF administration could be a useful strategy in the treatment prevention of ophthalmic diseases.

\section{Acknowledgements}

We thank Ms. Y. Tokuyama and Ms. A. Kitajima for their expert technical assistance, and also Mr. Hilary Eastwick-Field and Ms. K. Ando for the preparation of the manuscript. Grant support from: The Department of Transplantation for Regeneration Therapy (sponsored by Otsuka Pharmaceutical Company, Ltd.), Molecular Medical Science Institute, Otsuka Pharmaceutical Co., Ltd., Japan Immunoresearch Laboratories Co., Ltd. (JIMRO), Scientific Research (C) 18590388 and an award of alumni association of Kansai Medical University from Dr. Toshiko Kitanishi and Dr. Yasuko Shiozaki.

\section{Disclosure Statement}

The authors report no conflicts of interest.

\section{References}

1 Weaver CH, Buckner CD, Longin K, Appelbaum FR, Rowley S, Lilleby K, Miser J, Storb R, Hasen JA, Bensinger W: Syngeneic transplantation with peripheral blood mononuclear cells collected after the administration of recombinant human granulocyte colonystimulating factor. Blood 1993;82:19811984.

- Williams GT, Smith CA, Spooncer E, Dexter TM, Taylor DR: Haemopoietic colony stimulating factors promote cell survival by suppressing apoptosis. Nature 1990;343:76-79.

-3 Demetri GD, Griffin JD: Granulocyte colony-stimulating factor and its receptor. Blood 1991;78:2791-2808.

-4 Hu B, Yasui K: Effects of colony-stimulating factor (CSFs) on neutrophil apoptosis: possible roles at inflammation site. Int $J$ Hematol 1997;66:179-188.

5 Schneider A, Krüger C, Steigleder T, Weber D, Pitzer C, Laage R, Aronowski J, Maurer MH, Gassler N, Mier W, Hasselblatt M, Kollmar R, Schwab S, Sommer C, Bach A, Kuhn HG, Schäbitz WR: The hematopoietic factor G-CSF is a neuronal ligand that counteracts programmed cell death and drives neurogenesis. J Clin Invest 2005;115:2083-2098.

-6 Oishi A, Otani A, Sasabara M, Kojima H, Nakamura H, Yodoi Y, Yoshimura N: Granulocyte colony-stimulating factor protects retinal photoreceptor cells against light-induced damage. Invest Ophthalmol Vis Sci 2008;49: 5629-5635.
7 Frank T, Schlachetzki JC, Göricke B, Meuer K, Rohde G, Dietz GP, Bähr M, Schneider A, Weishaupt JH: Both systemic and local application of granulocyte-colony stimulating factor (G-CSF) is neuroprotective after retinal ganglion cell axotomy. BMC Neurosci 2009;10:49.

-8 Schäbitz WR, Kollmar R, Schwaninger M, Juettler E, Bardutzky J, Schölzke MN, Sommer C, Schwab S: Neuroprotective effect of granulocyte colony-stimulating factor after focal cerebral ischemia. Stroke 2003;34:745751.

-9 Komine-Kobayashi M, Zhang N, Liu M, Tanaka R, Hara H, Osaka A, Mochizuki H, Mizuno Y, Urabe T: Neuroprotective effect of recombinant human granulocyte colonystimulating factor in transient focal ischemia of mice. J Cereb Blood Metab 2006;26:402413.

10 Meuer K, Pitzer C, Teismann P, Krüger C, Göricke B, Laage R, Lingor P, Peters K, Schlachetzki JC, Kobayashi K, Dietz GP, Weber D, Ferger B, Schäbitz WR, Bach A, Schulz JB, Bähr M, Schneider A, Weishaupt JH: Granulocyte-colony stimulating factor is neuroprotective in a model of Parkinson's disease. J Neurochem 2006;97:675-686.
11 Tsai KJ, Tsai YC, Shen CK: G-CSF rescues the memory impairment of animal models of Alzheimer's disease. J Exp Med 2007;204: 1273-1280.

12 Koda M, Nishio T, Kamada T, Someya Y, Okawa A, Mori C, Yoshinaga K, Okada S, Moriya H, Yamazaki M: Granulocyte colony-stimulating factor (G-CSF) mobilizes bone marrow-derived cells into injured spinal cord and promotes functional recovery after compression-induced spinal cord injury in mice. Brain Res 2007;1149:223-231

13 Nefussy B, Artamonov I, Deutsch V, Naparstek E, Nagler A, Drory VE: Recombinant human granulocyte-colony stimulating factor administration for treating amyotrophic lateral sclerosis: a pilot study. Amyotroph Lateral Scler 2010;11:187-193.

-14 Shyu WC, Lin SZ, Lee CC, Liu DD, Li H Granulocyte colony-stimulating factor for acute ischemic stroke: a randomized controlled trial. CMAJ 2006;174:927-933.

15 Tsai RK, Chang CH, Wang HZ: Neuroprotective effects of recombinant human granulocyte colony-stimulating factor (G-CSF) in neurodegeneration after optic nerve crush in rats. Exp Eye Res 2008;87:242-250.

16 Tsai RK, Chang CH, Sheu MM, Huang ZL: Anti-apoptotic effects of human granulocyte colony-stimulating factor (G-CSF) on retinal ganglion cells after optic nerve crush are PI3K/AKT-dependent. Exp Eye Res 2010;90: 537-545. 
$\checkmark 17$ Kojima H, Otani A, Oishi A, Makiyama Y, Nakagawa S, Yoshimura N: Granulocyte colony-stimulating factor attenuates oxidative stress-induced apoptosis in vascular endothelial cells and exhibits functional and morphological protective effect in oxygen-induced retinopathy. Blood 2011;117:10911100.

$18 \mathrm{Bu}$ P, Basith B, Stubbs EB Jr, Perlman JI: Granulocyte colony-stimulating factor facilitates recovery of retinal function following retinal ischemic injury. Exp Eye Res 2010;91: 104-106.

-19 Büchi ER, Suivaizdis I, Fu J: Pressure-induced retinal ischemia in rats: an experimental model for quantitative study. Ophthalmologica 1991;203:138-147.

-20 Osborne NN, Chidlow G, Layton CJ, Wood JP, Casson RJ, Melena J: Optic nerve and neuroprotection strategies. Eye 2004;18:10751084.

21 Büchi ER: Cell death in the rat retina after a pressure-induced ischemia-reperfusion insult: an electron microscopic study. 1. Ganglion cell layer and inner nuclear layer. Exp Eye Res 1992;55:605-613.

-22 Rosenbaum DM, Rosenbaum PS, Gupta H, Singh M, Aggarwal A, Hall DH, Roth S, Kessler JA: The role of the $\mathrm{p} 53$ protein in the selective vulnerability of the inner retina to transient ischemia. Invest Ophthalmol Vis Sci 1998;39:2132-2139.

-23 Nucci C, Tartaglione R, Rombola L, Morrone LA, Fazzi E, Bagetta G: Neurochemical evidence to implicate elevated glutamate in the mechanisms of high intraocular pressure (IOP)-induced retinal ganglion cell death in rat. Neurotoxicology 2005;26:935-941.

-24 Takahashi K, Lam TT, Edward DP, Buchi ER, Tso MO: Protective effects of flunarizine on ischemic injury in the rat retina. Arch Ophthalmol 1992;110:862-870.
5 Zhu Y, Ohlemiller KK, McMahan BK, Gidday JM: Mouse models of retinal ischemic tolerance. Invest Ophthalmol Vis Sci 2002; 43:1903-1911.

-26 Shimamura N, Matchett G, Solaroglu I, Tsubokawa T, Ohkuma H, Zhang J: Inhibition of integrin alphavbeta3 reduces bloodbrain barrier breakdown in focal ischemia in rats. J Neurosci Res 2006;84:1837-1847.

27 Kuroiwa S, Katai N, Shibuki H, Kurokawa T, Umihira J, Nikaido T, Kametani K, Yoshimura N: Expression of cell cycle-related genes in dying cells in retinal ischemic injury. Invest Ophthalmol Vis Sci 1998;39:610617.

28 Kaneda K, Kashii S, Kurosawa T, Kaneko S, Akaike A, Honda Y, Minami M, Satoh M: Apoptotic DNA fragmentation and upregulation of Bax induced by transient ischemia of the rat retina. Brain Res 1999;815:11-20.

29 Solaroglu I, Cahill J, Tsubokawa T, Beskonakli E, Zhang JH: Granulocyte colony-stimulating factor protects the brain against experimental stroke via inhibition of apoptosis and inflammation. Neurol Res 2009;31:167172 .

30 Kawada H, Takizawa S, Takanashi T, Morita Y, Fujita J, Fukuda K, Takagi S, Okano H, Ando K, Hotta T: Administration of hematopoietic cytokines in the subacute phase after cerebral infarction is effective for functional recovery facilitating proliferation of intrinsic neural stem/progenitor cells and transition of bone marrow-derived neuronal cells. Circulation 2006;113:701-710.

- 31 Lee ST, Chu K, Jung KH, Ko SY, Kim EH, Sinn DI, Lee YS, Lo EH, Kim M, Roh JK: Granulocyte colony-stimulating factor enhances angiogenesis after focal cerebral ischemia. Brain Res 2005;1058:120-128.

32 Hasselblatt M, Jeibmann A, Riesmeier B, Maintz D, Schabitz WR: Granulocyte colony-stimulating factor (G-CSF) and G-CSF receptor expression in human ischemic stroke. Acta Neuropathol 2007;113:45-51.
3 Kirsch F, Kruger C, Schneiders A: The receptor for granulocyte colony-stimulating factor (G-CSF) is expressed in radial glia during development of the nervous system. BMC Dev Biol 2008;8:32-38.

-34 Nakazawa T, Shimura M, Tomita H, Akiyama H, Yoshioka Y, Kudou H, Tamai M: Intrinsic activation of PI3K/Akt signaling pathway and its neuroprotective effect against retinal injury. Curr Eye Res 2003;26: 55-63.

35 Manabe S, Lipton SA: Divergent NMDA signals leading to proapoptotic and antiapoptotic pathways in the rat retina. Invest Ophthalmol Vis Sci 2003;44:385-392.

- 36 Nakazawa T, Shimura M, Endo S, Takahashi H, Mori N, Tamai M: N-methyl-D-aspartic acid suppresses Akt activity through protein phosphatase in retinal ganglion cells. Mol Vis $2005 ; 11: 1173-1182$.

- 37 Kanamori A, Nakamura M, Nakanishi Y, Nagai A, Mukuno H, Yamada Y, Negi A: AKT is activated via insulin/IGF-1 receptor in rat retina with episcleral vein cauterization. Brain Res 2004;1022:195-204.

38 Kim HS, Park CK: Retinal ganglion cell death is delayed by activation of retinal intrinsic cell survival program. Brain Res 2005; 1057:17-28.

39 Levkovitch-Verbin H, Harizman N, Dardik R, Nisgav Y, Vander S, Melamed S: Regulation of cell death and survival pathways in experimental glaucoma. Exp Eye Res 2007; $85: 250-258$.

-40 Jan-Kolja S, Sevgi S, Matthias S, Rainer K, Sigrid N, Armin S, Wolf-Rudiger S: Effect of G-CSF treatment on neutrophil mobilization and neurological outcome after transient focal ischemia. Exp Neurol 2010;222: 108-113. 